Review Article

\title{
Neuroinflammatory Cytokines Induce Amyloid Beta Neurotoxicity through Modulating Amyloid Precursor Protein Levels/Metabolism
}

\author{
Fawaz Alasmari $\mathbb{D}^{\mathrm{D}}$, Musaad A. Alshammari, Abdullah F. Alasmari, \\ Wael A. Alanazi, and Khalid Alhazzani \\ Department of Pharmacology and Toxicology, College of Pharmacy, King Saud University, Riyadh, Saudi Arabia
}

Correspondence should be addressed to Fawaz Alasmari; ffalasmari@ksu.edu.sa

Received 11 July 2018; Revised 19 September 2018; Accepted 11 October 2018; Published 25 October 2018

Academic Editor: Stavros Baloyannis

Copyright (C) 2018 Fawaz Alasmari et al. This is an open access article distributed under the Creative Commons Attribution License, which permits unrestricted use, distribution, and reproduction in any medium, provided the original work is properly cited.

\begin{abstract}
Neuroinflammation has been observed in association with neurodegenerative diseases including Alzheimer's disease (AD). In particular, a positive correlation has been documented between neuroinflammatory cytokine release and the progression of the $\mathrm{AD}$, which suggests these cytokines are involved in $\mathrm{AD}$ pathophysiology. A histological hallmark of the $\mathrm{AD}$ is the presence of beta-amyloid $(\mathrm{A} \beta)$ plaques and tau neurofibrillary tangles. Beta-amyloid is generated by the sequential cleavage of beta $(\beta)$ and gamma $(\gamma)$ sites in the amyloid precursor protein (APP) by $\beta$ - and $\gamma$-secretase enzymes and its accumulation can result from either a decreased $\mathrm{A} \beta$ clearance or increased metabolism of APP. Previous studies reported that neuroinflammatory cytokines reduce the efflux transport of $\mathrm{A} \beta$, leading to elevated $\mathrm{A} \beta$ concentrations in the brain. However, less is known about the effects of neuroinflammatory mediators on APP expression and metabolism. In this article, we review the modulatory role of neuroinflammatory cytokines on APP expression and metabolism, including their effects on $\beta$ - and $\gamma$-secretase enzymes.
\end{abstract}

\section{Introduction}

The progression of neurodegenerative disorders including Alzheimer's disease $(\mathrm{AD})$ leads to death and other negative health consequences [1-3]. The prevalence of AD increases significantly with increasing age in the United States (US) [4]. Importantly, it has been estimated that, by 2050, the population of $\mathrm{AD}$ patients in the US will increase threefold over the number in 2000 [5]. Moreover, studies have found that more than 4.5 million new cases of dementia arise per year, $70 \%$ of which are attributed to $\mathrm{AD}[6,7]$. In the US, AD costs over $\$ 170$ billion every year [8]; reducing the progression of $\mathrm{AD}$ could provide beneficial consequences clinically and economically. Finding molecular therapeutic targets involved in the progression of $\mathrm{AD}$ is therefore highly important and studies exploring its causative factors are needed.

$\mathrm{AD}$ is accompanied by the formation of beta-amyloid $(\mathrm{A} \beta)$ plaques, neurodegeneration, and neuroinflammation [for review, see [11]]. Immune cells may produce autoimmune inflammation, which leads to the progression of neurodegenerative diseases including AD [for review, see [12]]. Triggering receptors expressed on myeloid cells 2 in microglial receptors for $\mathrm{A} \beta$ have been found to regulate the physiological and pathological functions of microglia [13]. A significant increase in neuroinflammatory cytokines release has been observed in animal models of $\mathrm{AD}$ [14]; these cytokines can cause neurodegeneration [15] and activation of microglia [16] that might further progress AD. The accumulation of $\mathrm{A} \beta$ in the brain also increases production of neuroinflammatory cytokines [14, 17]. Studies suggest that attenuation of $\mathrm{AD}$ symptoms is attributable at least in part to restored concentrations of neuroinflammatory cytokines, indicating that these molecules have a critical role in disease development [for review, see [18]]. Furthermore, the exposure of human neuronal and extraneuronal cells to an inflammatory cytokine such as interleukin-18 (IL-18) or a combination of interferon- $\gamma$ (IFN- $\gamma$ ) and tumor necrosis factor- $\alpha$ (TNF- $\alpha$ ) has been shown to lead to increased $A \beta$ production [19, 20]. This indicates that these cytokines modulate proteins 
that are responsible for generating $\mathrm{A} \beta$ [20]. The exposure to inflammatory cytokines also reduces $\mathrm{A} \beta$ transport [21, 22 , which might lead to accumulation of $\mathrm{A} \beta$ in the brain. This was confirmed by a later study, which showed that an anti-inflammatory agent reduced the accumulation of $\mathrm{A} \beta$ through upregulating ATP-binding cassette- $\mathrm{B} 1$ (ABCB1) [23], a protein involved in the clearance of $\mathrm{A} \beta$ from the brain into the vascular system $[24,25]$. A recent opinion article discussed the role of $\mathrm{ABCB} 1$ in $\mathrm{AD}$ progression through modulation of $\mathrm{A} \beta$ uptake [26].

A $\beta$ accumulation in the brain is one of the histological hallmarks associated with $\mathrm{AD}$ [for review, see [27]]. $\mathrm{A} \beta$ is formed through the sequential cleavage of the amyloid precursor protein (APP) by beta $(\beta-)$ and gamma $(\gamma-)$ secretase enzymes $[28,29]$. Prior exposure to neuroinflammatory cytokines has been associated with significant increases in the expression of APP in neuronal and glial cells [30] (Figure 1(b)). The regulatory role of neuroinflammatory cytokines on secretase enzymes has been discussed in previous reviews [31,32]. In this article, we highlighted the effects of neuroinflammatory cytokines on APP processing including APP secretases as well as A $\beta$ production and accumulation.

Regarding the effects of neuroinflammation on APP processing in human brain samples, studies have found that APP levels and metabolism are altered in postmortem brain tissues from AD patients $[33,34]$. A study reported that APP mRNA and protein expression level are increased in postmortem human temporal neocortex of AD patients [34]. Additionally, the activity and protein expression of $\beta$-secretase are increased in the neocortex of $\mathrm{AD}$ patients [33], suggesting that the formation of $\mathrm{A} \beta$ is further increased, leading to pathogenesis. For example, IL-1 levels are increased in the postmortem samples of hippocampus, thalamus, hypothalamus, and cortex of AD patients compared to those obtained from both individuals with vascular dementia and controls [35]. However, the effects of neuroinflammatory cytokines on APP cleaving enzymes merit further investigation. Since neuroinflammation is a common symptom associated with $\mathrm{AD}$, we discuss herein the modulatory role of neuroinflammatory cytokines on APP expression and metabolism in AD models.

1.1. APP. APP is a protein expressed ubiquitously in human body and APP brain isoform is processed into $A \beta$ and mainly localized in the neurons and synapses [36]. APP is the precursor of soluble APP- $\alpha$ and soluble APP- $\beta$ through cleavage by $\alpha$-secretase and $\beta$-secretase, respectively. $\mathrm{A} \beta$ is generated from the APP through sequential cleavage at the $\beta$ and $\gamma$ sites of the APP via $\beta$ - and $\gamma$-secretase enzymes, respectively $[28,29]$. Physiologically, it is involved in modulating neuronal development including differentiation, migration, and synaptogenesis, suggesting that APP is essential for maintaining homeostasis and synaptic plasticity [37-40]. In this article, we focus on the role of APP and its therapeutic implications in the AD.

1.1.1. Role of APP Expression/Metabolism in AD. The expression of APP cleaving enzymes is increased in the brain cortex of AD patients [41] and the mRNA expression of APP was also increased in AD rat models [42], and these effects are also associated with elevated brain $\mathrm{A} \beta$ concentrations [for review, see [43]]. It has been suggested that the activities of $\beta$ - and $\gamma$-secretase enzymes are enhanced in the brains of AD individuals $[33,44]$, which could elevate brain $\mathrm{A} \beta$ levels leading to formation of senile plaques (A $\beta$ deposit) [for review, see [45]]. Pharmacological targeting of $\beta$ - and $\gamma$-secretase could, therefore, attenuate APP-increased A $\beta$ concentrations $[46,47]$, which might reduce AD-associated symptoms in AD animal models. This hypothesis is supported by reviews indicating that $\beta$ - and $\gamma$-secretase inhibitors attenuate the behavioral symptoms of AD in animals $[48,49]$. Specifically, the expression and functions of these enzymes were altered in the brains of $\mathrm{AD}$ treated model [33, 41, 50]. Importantly, a $\gamma$-secretase enzyme modulator, CHF5074, has been found to attenuate the number and occupation area of $\mathrm{A} \beta$ plaques in the cortex and hippocampus of an $\mathrm{AD}$ model, and improved AD-associated behavioral symptoms were demonstrated using swimming path test [51]. This study found that CHF5074 also reduced plaques-occupied area in microglia suggesting that this compound can attenuate neuroinflammation associated with AD. However, studies are warranted to explore the effects of neuroinflammatory cytokines on the activity and expression of $\beta$ - and $\gamma$-secretase enzymes in $\mathrm{AD}$ models.

In addition to the role of APP metabolism in AD, the overexpression of APP has been used extensively to develop $\mathrm{AD}$ models $[52,53]$. A previous study found that APP expression level was increased in $\mathrm{AD}$ models $[34,54]$ indicating that increase in APP expression may cause accumulation of $A \beta$ in the brain. Interestingly, exposure to neuroinflammatory cytokines increased the expression of APP using neuronal and nonneuronal cell lines $[20,30,55]$. These findings suggest that neuroinflammatory cytokines could cause accumulation of $A \beta$ in the brain either through increased expression of APP or by decreasing the transport of $\mathrm{A} \beta$ into the vascular system. It is important to note that both protein and mRNA expression of APP were upregulated [34], and other reports have also shown that apolipoprotein E4 (APOE4) secreted glia stimulated APP transcription and $\mathrm{A} \beta$ production in human cultured neurons [56]. This suggests that these inflammatory cytokines might upregulate APP through modulating the expression of its transcription factors; however, this hypothesis needs further investigation. In this article, we review the effects of proinflammatory cytokines produced in $\mathrm{AD}$ models on the mRNA and protein expression of APP.

1.1.2. APP Processing as a Therapeutic Target for Attenuating $A D$ Pathology. As discussed earlier, APP metabolism is a process involved in the production of $A \beta$ in the brain $[28,29]$. Therefore, modulating enzymes that cleave APP into $A \beta$ could attenuate the concentrations of $A \beta[51,57-59]$, which might lead to the attenuation of $\mathrm{AD}$ behavioral symptoms $[51,58]$. The daily treatment of transgenic model of the $\mathrm{AD}$ with a $\gamma$-secretase enzyme modulator for seven months has been shown to reduce the concentrations of $A \beta$ in the cortex and hippocampus [57]. In another study, mice with $\mathrm{AD}$ that were exposed to methylene blue for three months also had decreased productions and concentrations of $\mathrm{A} \beta 1-40$ and 


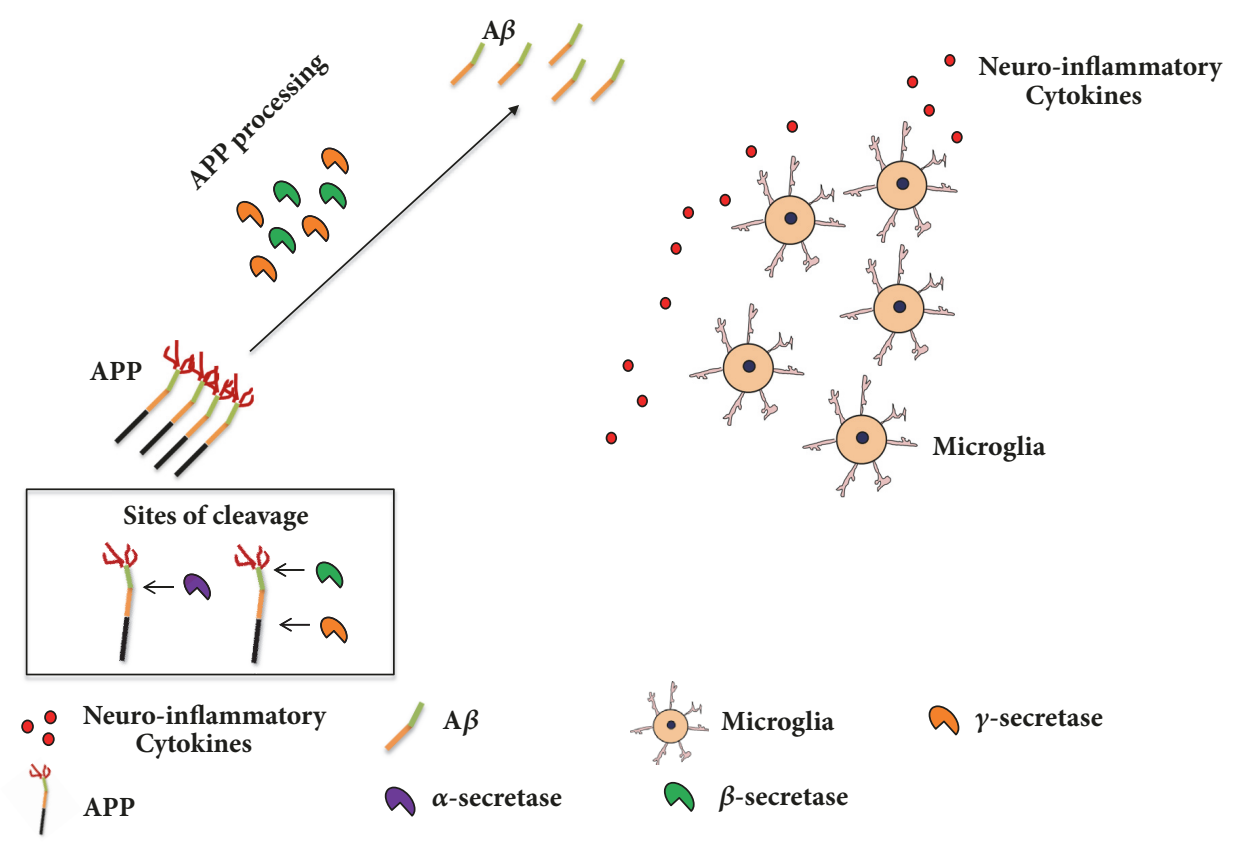

(a)

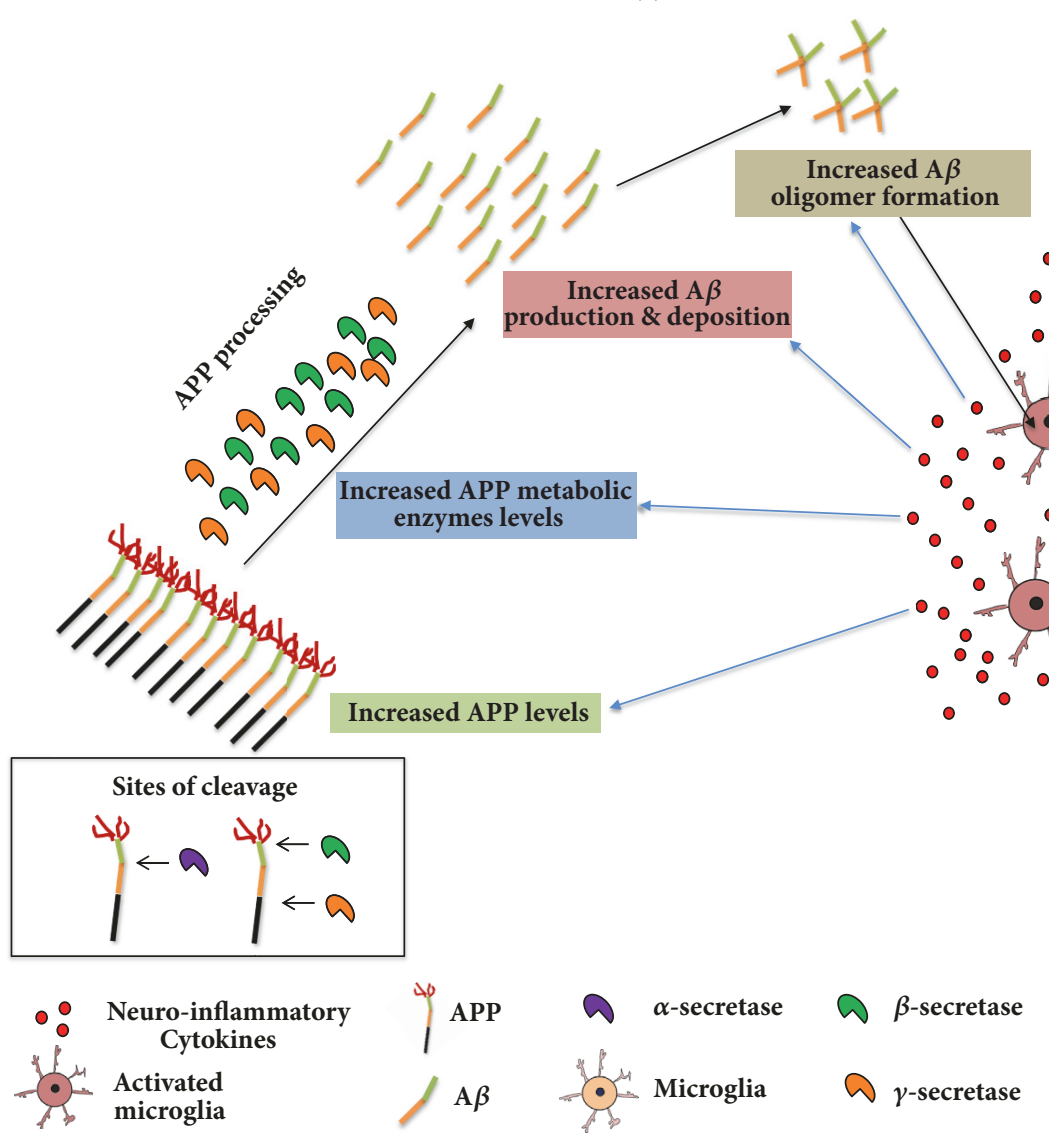

(b)

FIGURE 1: Schematic diagram for the effects of neuroinflammatory cytokines on amyloid precursor protein (APP) processing and beta-amyloid $(\mathrm{A} \beta)$ production. Amyloid precursor proteins (APP) are cleaved by beta $(\beta)$ and gamma $(\gamma)$ sites in the APP by $\beta$ - and $\gamma$-secretase enzymes producing $\mathrm{A} \beta$ in the brain. (a) Normal levels and activity of APP, APP metabolic enzymes, and neuroinflammatory cytokines in control brain. (b) In Alzheimer disease (AD), $A \beta$ is accumulated in the brain leading to formation of $A \beta$ oligomers. This effect leads to activation of microglia, which increases the production of neuroinflammatory cytokines. These cytokines increase APP levels, upregulate $\beta$-secretase and $\gamma$-secretase, and decrease $\mathrm{A} \beta$ clearance in the brain. These effects result in further increase in $\mathrm{A} \beta$ concentrations and formation of $\mathrm{A} \beta$ oligomers and plaques. 
A $\beta 1-42$ in the cortex via inhibitory effects on the $\beta$-secretase enzyme [58]. This effect was associated with the attenuation of $\mathrm{AD}$ behavioral symptoms such as cognition, locomotion, and rearing. Similarly, a three-month treatment of transgenic $\mathrm{AD}$ mice model with selenomethionine decreased the deposition and production of $\mathrm{A} \beta$ in the cortex and hippocampus through modulating $\beta$-secretase enzyme in the same brain regions [59]. Together, these findings indicate that modulating either secretase enzymes attenuates $\mathrm{A} \beta$ plaques and consequently the associated behavioral symptoms.

Targeting the expression of APP is another therapeutic strategy for attenuating $\mathrm{A} \beta$ deposition $[60,61]$ and therefore potentially limiting $\mathrm{AD}$ progression. In $\mathrm{CHO} \mathrm{APP}_{751 \mathrm{SW}}$ cells treated with 2-[(pyridine-2-ylmethyl)-amino]-phenol (2-PMAP), both APP level and the production of $\mathrm{A} \beta \mathrm{x}_{-}{ }_{40}$ and $A \beta \mathrm{X}^{-}{ }_{42}$ were inhibited in a dose-dependent manner [60]. This study also found that the inhibitory effect of 2-PMAP on APP was realized through a mechanism affecting APP translation. In addition, 2-PMAP was able to reduce the length of APP and its fragmentation [60]. These effects were associated with improved memory performance in a transgenic mouse model. Another study found that treatment of an $\mathrm{AD}$ mouse model with icariin, a compound from Chinese herb Epimedium spp., reduced the burden and production of $\mathrm{A} \beta$ in the hippocampus through reducing the levels of APP and $\beta$-secretase [61]. These studies confirmed that APP level plays a crucial role in the deposition of $\mathrm{A} \beta$ in the brain and therefore in neurodegeneration and neuroinflammation. A novel approach would focus on targeting APP modifications. The selective inhibition of APP colocalization with BACE1 and $\gamma$-secretase could lead to a couple of therapeutic benefits. First, it would have minimal impact on substrates acting by binding to $\beta$ - and $\gamma$-secretase. Second, it would directly affect APP trafficking leading to reducing in the colocalization of APP with $\beta$ - and $\gamma$-secretase $[62,63]$. Thus, modulating the levels of APP and secretase enzymes are promising therapeutic targets for attenuating $\mathrm{AD}$ pathogenesis.

1.2. Role of Neuroinflammatory Cytokines in $A D$. Increased production of neuroinflammatory cytokines is broadly associated with neurological disorders, including $\operatorname{AD}[20,64,65]$. For instance, high concentrations of IL-1, IL-17, IFN- $\gamma$, and TNF- $\alpha$ are observed in the brains of AD models [35, 66, 67]. Moreover, increased secretion of IL-17 and IFN- $\gamma$ from T cells has been demonstrated in a transgenic AD mouse model, and treatment with anti-IFN- $\gamma$ antibody has been shown to attenuate $\mathrm{A} \beta$ deposition induced by $\mathrm{CD} 4(+) \mathrm{T}$ cells [66]. In addition, increased neuroinflammatory cytokines levels have been observed in human brain tissues [35]. Moreover, the combination of adeno-associated virus 1 expressing murine IL- 6 and an A $\beta$ suppressor induced further improvement in plaque clearance in transgenic mice [68]. Additionally, decoy receptor 3 (DcR3), a TNF soluble protein, has been found to reduce the accumulation of amyloid plaque, an effect associated with reduced $\mathrm{A} \beta$-increased anti-inflammatory cytokines production from microglia [69]. It is important to note that overexpression of IL-17A, a marker around deposits of accumulated $\mathrm{A} \beta$, reduced the level of $\mathrm{A} \beta$ in the hippocampus and cerebrospinal fluid. This effect was associated with increased $\mathrm{ABCA} 1$ expression; a protein transports $\mathrm{A} \beta$ from brain into the circulatory system [70]. High concentrations of TNF- $\alpha$ were observed in the hippocampus of a mouse AD model, which induced synaptic plasticity and transmission of glutamate [67]. These data provide evidence for targets of neuroinflammatory cytokines that may also provide pharmacological targets for attenuating the pathogenesis of $\mathrm{AD}$.

To support these findings, targeting neuroinflammatory cytokines has been shown to attenuate AD behavioral symptoms in animals $[66,67,71,72]$. A study found that anti-IFN$\gamma$ attenuated impaired cognition in a transgenic AD mouse model [66]. Another model study showed that pretreatment with a TNF- $\alpha$ inhibitor prevented synaptic deficiency induced by increased secretion of TNF- $\alpha$ in the hippocampus [67]. Moreover, treatment with a TNF- $\alpha$ synthesis inhibitor, $3,6^{\prime}$-dithiothalidomide, attenuated impaired memory associated with neuroinflammation and also reduced neurogenesis in the hippocampus that had been induced by $\mathrm{A} \beta$ peptide [71]. Pretreatment with $3,6^{\prime}$-dithiothalidomide of an $\mathrm{AD}$ mouse model also attenuated $\mathrm{A} \beta$ peptide-induced memory deficiency, while chronic exposure reduced impaired cognition and memory dysfunction, effects that were so associated with reduced APP and A $\beta$ plaque levels [73]. Furthermore, attenuation of memory dysfunction has been observed in mice treated with a TNF- $\alpha$ receptor inhibitor [72]. Taken together, these results suggest that neuroinflammatory cytokines in general and TNF- $\alpha$, in particular, are implicated in $\mathrm{AD}$ pathogenesis.

\section{Effects of Neuroinflammatory Cytokines on APP in AD Models}

From our previous section, there is evidence that exposure to neuroinflammatory cytokines may modulate APP levels $[73,74]$ and metabolism $[75,76]$ (Figure 1(b)) which might be targeted for attenuating $\mathrm{AD}$ progression. These effects were not observed with the control group (Figure 1(a)). For example, increased APP expression has been found to lead to the increase of brain $A \beta$ levels [60]. In addition, modulation of APP metabolism attenuated deposition of $A \beta$ [57], which might lead to improved AD-behavioral symptoms.

\subsection{Effects of Neuroinflammatory Cytokines on APP Expres-} sion/Level. Several studies found that APP expression is a key factor involved in the development of $\mathrm{AD}[34,52]$. Importantly, the expression/level of APP is positively correlated with the concentrations of $\mathrm{A} \beta$ in the brain $[60,61]$. Studies have been performed to determine the causative factors involved in increased APP expression. In AD model, the neuroinflammatory cytokines have been found to modulate the expression level of APP [30]. This suggests that neuroinflammation associated with $\mathrm{AD}$ plays a substantial role in elevating the expression level of the APP which leads to increased $\mathrm{A} \beta$ production. This effect results in the formation of $\mathrm{A} \beta$ plaque and oligomers that lead to neurodegeneration, an effect involved in $\mathrm{AD}$ pathogenesis [for review, see [77]].

Supporting the hypothesis that neuroinflammation modulates $\mathrm{AD}$ development, the exposure to neuroinflammatory 
cytokines increases APP expression [30], which might modulate the level of $\mathrm{A} \beta$ in animals developing $\mathrm{AD}$. A prior study reported that the exposure to IL- $1 \beta$ and IL- 1 increased the mRNA expression of APP in endothelial and neuronal cells [30]. Similarly, the exposure to IL-1 increased the level of APP transcripts in endothelial cells from human umbilical veins [78]. We suggest here that the synthesis of APP is modulated by neuroinflammatory cytokines including IL-1, TNF- $\alpha$, and IFN- $\gamma$ [78-80]. A study found that the level of APP constitutive shedding is regulated by TNF- $\alpha$ converting enzyme [79]. Moreover, the exposure to TNF- $\alpha$ or IFN$\gamma$ upregulated APP in both neurons and astrocytes [80]. These findings provide evidence for the potential effects of neuroinflammation on the amyloid precursor system in the progression of the AD.

2.2. Neuroinflammatory Cytokines Modulate APP Metabolism. Neuroinflammatory cytokines have also been shown to modulate APP metabolic enzymes including $\beta$ - and $\gamma$ secretase $[75,76,80-82]$. Interleukins, TNF- $\alpha$, and IFN$\gamma$ are known to stimulate $\gamma$-secretase enzyme activity; this effect was associated with increased production of $\mathrm{A} \beta$ and the APP intracellular domain [75]. TNF- $\alpha$ and IFN- $\gamma$ have been shown to enhance $\beta$-secretase enzyme expression in a transgenic mouse model of the $\mathrm{AD}$, increasing $\mathrm{A} \beta$ deposition and reducing its uptake [76]. Treatment with sulindac sulfide, an anti-inflammatory agent, restored lipopolysaccharide (LPS)-induced $\beta$-secretase expression in neuron cells [80]. In addition, this study found that this compound could reduce the secretion of $\mathrm{A} \beta_{42}$ in neurons treated with LPS Furthermore, genetic deletion of the TNF- $\alpha$ death receptor was associated with reduced $\beta$-secretase enzyme activity and expression in AD mice [81]. This effect was also associated with reduced microglia activation and reduced $\mathrm{A} \beta$ production and deposits. Further support comes from $5 \mathrm{XFAD} / \mathrm{TNF}-\alpha^{-/-}$mice, which have significantly decreased protein expression of $\beta$-secretase enzyme and $\mathrm{A} \beta$ deposition [82]. Finally, the TNF- $\alpha$ converting enzyme has been found to regulate $\gamma$-secretase enzyme activity [83]. These data shed light on the potential effects of inflammatory cytokines on $\beta$ - and $\gamma$-secretase and $\mathrm{A} \beta$ system dysregulation in $\mathrm{AD}$ models. More studies are required to investigate whether these neuroinflammatory cytokines could be pharmacologically targeted to attenuate $\mathrm{AD}$-associated symptoms.

\section{Conclusion}

Neuroinflammation associated with $\mathrm{AD}$ is suggested to progress $\mathrm{AD}$ in part by increasing the accumulation of $\mathrm{A} \beta$ in the brain, which induces $\mathrm{A} \beta$ plaques and leads to neurodegeneration and microglial activation. Moreover, the release of neuroinflammatory cytokines is increased in $\mathrm{AD}$ models; these cytokines reduce the clearance of $\mathrm{A} \beta$ and increase its production, in part by increasing the expression/levels of APP (Figure 1(b)). The cytokines also modulate APP metabolism leading to AD pathogenesis. Studies are warranted to investigate the effects of compounds that have anti-inflammatory properties on $\mathrm{AD}$ progression.

\section{Conflicts of Interest}

The authors declare no conflicts of interest.

\section{Acknowledgments}

The authors would like to thank the Deanship of Scientific Research and College of Pharmacy Research Center at King Saud University for their support.

\section{References}

[1] L. Duckett, "Alzheimer's dementia: morbidity and mortality.", Journal of insurance medicine (New York, N.Y.), vol. 33, no. 3, pp. 227-234, 2001.

[2] M. Ganguli, H. H. Dodge, C. Shen, R. S. Pandav, and S. T. DeKosky, "Alzheimer disease and mortality: a 15-year epidemiological study," JAMA Neurology, vol. 62, no. 5, pp. 779-784, 2005.

[3] B. D. James, S. E. Leurgans, L. E. Hebert, P. A. Scherr, K. Yaffe, and D. A. Bennett, "Contribution of Alzheimer disease to mortality in the United States," Neurology, vol. 82, no. 12, pp. 1045-1050, 2014.

[4] W. A. Rocca, R. C. Petersen, D. S. Knopman et al., "Trends in the incidence and prevalence of Alzheimer's disease, dementia, and cognitive impairment in the United States," Alzheimer's \& Dementia, vol. 7, no. 1, pp. 80-93, 2011.

[5] L. E. Hebert, P. A. Scherr, J. L. Bienias, D. A. Bennett, and D. A. Evans, "Alzheimer disease in the US population: prevalence estimates using the 2000 census," JAMA Neurology, vol. 60, no. 8, pp. 1119-1122, 2003.

[6] L. E. Hebert, J. Weuve, P. A. Scherr, and D. A. Evans, "Alzheimer disease in the United States (2010-2050) estimated using the 2010 census," Neurology, vol. 80, no. 19, pp. 1778-1783, 2013.

[7] C. Reitz and R. Mayeux, "Alzheimer disease: epidemiology, diagnostic criteria, risk factors and biomarkers," Biochemical Pharmacology, vol. 88, no. 4, pp. 640-651, 2014.

[8] C. L. Gooch, E. Pracht, and A. R. Borenstein, "The burden of neurological disease in the United States: A summary report and call to action," Annals of Neurology, vol. 81, no. 4, pp. 479484, 2017.

[9] P. L. McGeer and E. G. McGeer, "The inflammatory response system of brain: implications for therapy of Alzheimer and other neurodegenerative diseases," Brain Research Reviews, vol. 21, no. 2, pp. 195-218, 1995.

[10] P. Eikelenboom, R. Veerhuis, W. Scheper, A. J. M. Rozemuller, W. A. Van Gool, and J. J. M. Hoozemans, "The significance of neuroinflammation in understanding Alzheimer's disease," Journal of Neural Transmission, vol. 113, no. 11, pp. 1685-1695, 2006.

[11] E. Karran, M. Mercken, and B. D. Strooper, “The amyloid cascade hypothesis for Alzheimer's disease: an appraisal for the development of therapeutics," Nature Reviews Drug Discovery, vol. 10, no. 9, pp. 698-712, 2011.

[12] A. Sommer, B. Winner, and I. Prots, "The Trojan horse Neuroinflammatory impact of $\mathrm{T}$ cells in neurodegenerative diseases," Molecular Neurodegeneration, vol. 12, no. 1, 2017.

[13] Y. Zhao, X. Wu, X. Li et al., “TREM2 Is a Receptor for $\beta$-Amyloid that Mediates Microglial Function," Neuron, vol. 97, no. 5, pp. 1023-1031.e7, 2018. 
[14] N. S. Patel, D. Paris, V. Mathura, A. N. Quadros, F. C. Crawford, and M. J. Mullan, "Inflammatory cytokine levels correlate with amyloid load in transgenic mouse models of Alzheimer's disease," Journal of Neuroinflammation, vol. 2, no. 1, article 9, 2005.

[15] J. A. Smith, A. Das, S. K. Ray, and N. L. Banik, "Role of proinflammatory cytokines released from microglia in neurodegenerative diseases," Brain Research Bulletin, vol. 87, no. 1, pp. 10-20, 2012.

[16] R. Kuno, J. Wang, J. Kawanokuchi, H. Takeuchi, T. Mizuno, and A. Suzumura, "Autocrine activation of microglia by tumor necrosis factor- $\alpha$, Journal of Neuroimmunology, vol. 162, no. 1-2, pp. 89-96, 2005.

[17] S. Liu, Y. Liu, W. Hao et al., "TLR2 is a primary receptor for Alzheimer's amyloid beta peptide to trigger neuroinflammatory activation," The Journal of Immunology, vol. 188, no. 3, pp. 10981107, 2012.

[18] M. R. Bronzuoli, A. Iacomino, L. Steardo, and C. Scuderi, "Targeting neuroinflammation in Alzheimer's disease," Journal of Inflammation Research, vol. 9, pp. 199-208, 2016.

[19] I. Blasko, F. Marx, E. Steiner, T. Hartmann, and B. GrubeckLoebenstein, "TNF $\alpha$ plus IFN $\gamma$ induce the production of alzheimer $\beta$-amyloid peptides and decrease the secretion of APPs," The FASEB Journal, vol. 13, no. 1, pp. 63-68, 1999.

[20] E. M. Sutinen, T. Pirttilä, G. Anderson, A. Salminen, and J. O. Ojala, "Pro-inflammatory interleukin-18 increases Alzheimer's disease-associated amyloid- $\beta$ production in human neuronlike cells," Journal of Neuroinflammation, vol. 9, no. 1, 2012.

[21] D. A. Evseenko, J. W. Paxton, and J. A. Keelan, "Independent regulation of apical and basolateral drug transporter expression and function in placental trophoblasts by cytokines, steroids, and growth factors," Drug Metabolism and Disposition, vol. 35, no. 4, pp. 595-601, 2007.

[22] M. Iqbal, H. L. Ho, S. Petropoulos, V. G. Moisiadis, W. Gibb, and S. G. Matthews, "Pro-inflammatory cytokine regulation of Pglycoprotein in the developing blood-brain barrier," PLOS ONE, vol. 7, no. 8, 2012.

[23] H. Qosa, Y. S. Batarseh, M. M. Mohyeldin, K. A. El Sayed, J. N. Keller, and A. Kaddoumi, "Oleocanthal Enhances Amyloid$\beta$ Clearance from the Brains of TgSwDI Mice and in Vitro across a Human Blood-Brain Barrier Model," ACS Chemical Neuroscience, vol. 6, no. 11, pp. 1849-1859, 2015.

[24] H. Qosa, A. H. Abuznait, R. A. Hill, and A. Kaddoumi, "Enhanced brain amyloid- $\beta$ clearance by rifampicin and caffeine as a possible protective mechanism against alzheimer's disease," Journal of Alzheimer's Disease, vol. 31, no. 1, pp. 151-165, 2012.

[25] A. Brenn, M. Grube, G. Jedlitschky et al., "St. John's Wort reduces beta-amyloid accumulation in a double transgenic Alzheimer's disease mouse model - Role of P-glycoprotein," Brain Pathology, vol. 24, no. 1, pp. 18-24, 2014.

[26] F. Alasmari, C. R. Ashby, F. S. Hall, Y. Sari, and A. K. Tiwari, "Modulation of the ATP-Binding Cassette B1 Transporter by Neuro-Inflammatory Cytokines: Role in the Pathogenesis of Alzheimer's Disease," Frontiers in Pharmacology, vol. 9, 2018.

[27] M. P. Murphy and H. LeVine III, "Alzheimer's disease and the amyloid- $\beta$ peptide," Journal of Alzheimer's Disease, vol. 19, no. 1 , pp. 311-323, 2010.

[28] R. J. O’Brien and P. C. Wong, "Amyloid precursor protein processing and alzheimer's disease," Annual Review of Neuroscience, vol. 34, pp. 185-204, 2011.
[29] Y.-W. Zhang, R. Thompson, H. Zhang, and H. Xu, "APP processing in Alzheimer's disease," Molecular Brain, vol. 4, no. 1, article 3, 2011.

[30] G. Forloni, F. Demicheli, S. Giorgi, C. Bendotti, and N. Angeretti, "Expression of amyloid precursor protein mRNAs in endothelial, neuronal and glial cells: modulation by interleukin1," Brain Research, vol. 16, no. 1-2, pp. 128-134, 1992.

[31] M. Sastre, J. Walter, and S. M. Gentleman, "Interactions between APP secretases and inflammatory mediators," Journal of Neuroinflammation, vol. 5, article 25, 2008.

[32] M. T. Heneka, M. J. Carson, J. El. Khoury et al., "Neuroinflammation in Alzheimer's disease," The Lancet Neurology, vol. 14, no. 4, pp. 388-405, 2015.

[33] H. Fukumoto, B. S. Cheung, B. T. Hyman, and M. C. Irizarry, " $\beta$-Secretase protein and activity are increased in the neocortex in Alzheimer disease," JAMA Neurology, vol. 59, no. 9, pp. 13811389, 2002.

[34] T. Matsui, M. Ingelsson, H. Fukumoto et al., "Expression of APP pathway mRNAs and proteins in Alzheimer's disease," Brain Research, vol. 1161, no. 1, pp. 116-123, 2007.

[35] R. Cacabelos, X. A. Álvarez, L. Fernandez-Novoa et al., "Brain interleukin- $1 \beta$ in Alzheimer's disease and vascular dementia," Methods and Findings in Experimental and Clinical Pharmacology, vol. 16, no. 2, pp. 141-151, 1994.

[36] H.-S. Hoe, H.-K. Lee, and D. T. S. Pak, "The upside of APP at synapses," CNS Neuroscience \& Therapeutics, vol. 18, no. 1, pp. 47-56, 2012.

[37] E. A. Milward, R. Papadopoulos, S. J. Fuller et al., "The amyloid protein precursor of Alzheimer's disease is a mediator of the effects of nerve growth factor on neurite outgrowth," Neuron, vol. 9, no. 1, pp. 129-137, 1992.

[38] Qiui W. Q., A. Ferreira, C. Miller, E. H. Koo, and D. J. Selkoe, "Cell-surface $\beta$-amyloid precursor protein stimulates neurite outgrowth of hippocampal neurons in an isoform-dependent manner," The Journal of Neuroscience, vol. 15, no. 3, pp. 21572167, 1995.

[39] I. Caillé, B. Allinquant, E. Dupont et al., "Soluble form of amyloid precursor protein regulates proliferation of progenitors in the adult subventricular zone," Development, vol. 131, no. 9, pp. 2173-2181, 2004.

[40] C. Priller, T. Bauer, G. Mitteregger, B. Krebs, H. A. Kretzschmar, and J. Herms, "Synapse formation and function is modulated by the amyloid precursor protein," The Journal of Neuroscience, vol. 26, no. 27, pp. 7212-7221, 2006.

[41] R. M. D. Holsinger, C. A. McLean, K. Beyreuther, C. L. Masters, and G. Evin, "Increased expression of the amyloid precursor $\beta$ secretase in Alzheimer's disease," Annals of Neurology, vol. 51, no. 6, pp. 783-786, 2002.

[42] Q. Li, M. Chen, H. Liu, L. Yang, and G. Yang, "Expression of APP, BACE1, AChE and ChAT in an AD model in rats and the effect of donepezil hydrochloride treatment," Molecular Medicine Reports, vol. 6, no. 6, pp. 1450-1454, 2012.

[43] R. Vassar, D. M. Kovacs, R. Yan, and P. C. Wong, "The $\beta$ secretase enzyme BACE in health and Alzheimer's disease: Regulation, cell biology, function, and therapeutic potential," The Journal of Neuroscience, vol. 29, no. 41, pp. 12787-12794, 2009.

[44] N. Kakuda, M. Shoji, H. Arai et al., "Altered $\gamma$-secretase activity in mild cognitive impairment and Alzheimer's disease," EMBO Molecular Medicine, vol. 4, no. 4, pp. 344-352, 2012. 
[45] C. K. Glass, K. Saijo, B. Winner, M. C. Marchetto, and F. H. Gage, "Mechanisms underlying inflammation in neurodegeneration," Cell, vol. 140, no. 6, pp. 918-934, 2010.

[46] J. Cui, X. Wang, X. Li et al., “Targeting the $\gamma$-/ $\beta$-secretase interaction reduces $\beta$-amyloid generation and ameliorates Alzheimer's disease-related pathogenesis," Cell Discovery, vol. 1, p. 15021, 2015.

[47] K. Strömberg, S. Eketjäll, B. Georgievska et al., "Combining an amyloid-beta $(\mathrm{A} \beta)$ cleaving enzyme inhibitor with a $\gamma$-secretase modulator results in an additive reduction of $\mathrm{A} \beta$ production," FEBS Journal, vol. 282, no. 1, pp. 65-73, 2015.

[48] B. P. Imbimbo and G. A. M. Giardina, " $\gamma$-secretase inhibitors and modulators for the treatment of Alzheimer's disease: disappointments and hopes," Current Topics in Medicinal Chemistry, vol. 11, no. 12, pp. 1555-1570, 2011.

[49] R. Yan and R. Vassar, "Targeting the $\beta$ secretase BACE1 for Alzheimer's disease therapy," The Lancet Neurology, vol. 13, no. 3, pp. 319-329, 2014.

[50] M. Szaruga, S. Veugelen, M. Benurwar et al., "Qualitative changes in human $\gamma$-secretase underlie familial Alzheimer's disease," The Journal of Experimental Medicine, vol. 212, no. 12, pp. 2003-2013, 2015.

[51] B. P. Imbimbo, B. Hutter-Paier, G. Villetti et al., "CHF5074, a novel $\gamma$-secretase modulator, attenuates brain $\beta$-amyloid pathology and learning deficit in a mouse model of Alzheimer's disease," British Journal of Pharmacology, vol. 156, no. 6, pp. 982-993, 2009.

[52] X. Zhang, H. Li, Y. Mao et al., "An Over Expression APP Model for Anti-Alzheimer Disease Drug Screening Created by Zinc Finger Nuclease Technology," PLoS ONE, vol. 8, no. 11, p. e75493, 2013.

[53] H. Sasaguri, P. Nilsson, S. Hashimoto et al., "APP mouse models for Alzheimer's disease preclinical studies," EMBO Journal, vol. 36, no. 17, pp. 2473-2487, 2017.

[54] H. Arai, V. M. -. Lee, M. L. Messinger, B. D. Greenberg, D. E. Lowery, and J. Q. Trojanowski, "Expression patterns of $\beta$-amyloid precursor protein ( $\beta$-APP) in neural and nonneural human tissues from alzheimer's disease and control subjects," Annals of Neurology, vol. 30, no. 5, pp. 686-693, 1991.

[55] G. Sommer, S. Kralisch, J. Lipfert et al., "Amyloid precursor protein expression is induced by tumor necrosis factor $\alpha$ in 3T3L1 adipocytes," Journal of Cellular Biochemistry, vol. 108, no. 6, pp. 1418-1422, 2009.

[56] Y.-W. A. Huang, B. Zhou, M. Wernig, and T. C. Südhof, "ApoE2, ApoE3, and ApoE4 Differentially Stimulate APP Transcription and A $\beta$ Secretion," Cell, vol. 168, no. 3, pp. 427-441.e21, 2017.

[57] M. Z. Kounnas, A. M. Danks, S. Cheng et al., "Modulation of $\gamma$-Secretase Reduces $\beta$-Amyloid Deposition in a Transgenic Mouse Model of Alzheimer's Disease," Neuron, vol. 67, no. 5, pp. 769-780, 2010.

[58] T. Mori, N. Koyama, T. Segawa et al., "Methylene blue modulates $\beta$-secretase, reverses cerebral amyloidosis, and improves cognition in transgenic mice," The Journal of Biological Chemistry, vol. 289, no. 44, pp. 30303-30317, 2014.

[59] Z.-H. Zhang, C. Chen, Q.-Y. Wu et al., "Selenomethionine reduces the deposition of beta-amyloid plaques by modulating $\beta$-secretase and enhancing selenoenzymatic activity in a mouse model of Alzheimer's disease," Metallomics, vol. 8, no. 8, pp. 782-789, 2016.

[60] A. A. Asuni, M. Guridi, J. E. Pankiewicz, S. Sanchez, and M. J. Sadowski, "Modulation of amyloid precursor protein expression reduces $\beta$-amyloid deposition in a mouse model," Annals of Neurology, vol. 75, no. 5, pp. 684-699, 2014.

[61] L. Zhang, C. Shen, J. Chu, R. Zhang, Y. Li, and L. Li, "Icariin decreases the expression of APP and BACE-1 and reduces the $\beta$-amyloid burden in an APP transgenic mouse model of Alzheimer's disease," International Journal of Biological Sciences, vol. 10, no. 2, pp. 181-191, 2014.

[62] A. Kimura, S. Hata, and T. Suzuki, "Alternative selection of site APP-cleaving enzyme 1 (BACE1) cleavage sites in amyloid $\beta$ protein precursor (APP) harboring protective and pathogenic mutations within the A $\beta$ sequence," The Journal of Biological Chemistry, vol. 291, no. 46, pp. 24041-24053, 2016.

[63] X. Wang, X. Zhou, G. Li, Y. Zhang, Y. Wu, and W. Song, "Modifications and trafficking of APP in the pathogenesis of alzheimer's disease," Frontiers in Molecular Neuroscience, vol. 10, 2017.

[64] K. Chu, S.-T. Lee, D.-I. Sinn et al., "Pharmacological induction of ischemic tolerance by glutamate transporter-1 (EAAT2) upregulation," Stroke, vol. 38, no. 1, pp. 177-182, 2007.

[65] J. Wei, X. Pan, Z. Pei et al., "The beta-lactam antibiotic, ceftriaxone, provides neuroprotective potential via anti-excitotoxicity and anti-inflammation response in a rat model of traumatic brain injury," Journal of Trauma and Acute Care Surgery, vol. 73, no. 3, pp. 654-660, 2012.

[66] T. C. Browne, K. McQuillan, R. M. McManus, J.-A. O’Reilly, K. H. G. Mills, and M. A. Lynch, "IFN- $\gamma$ production by amyloid $\beta$ specific Thl cells promotes microglial activation and increases plaque burden in a mouse model of Alzheimer's disease," The Journal of Immunology, vol. 190, no. 5, pp. 2241-2251, 2013.

[67] C. Cavanagh, Y. C. Tse, H.-B. Nguyen et al., "Inhibiting tumor necrosis factor- $\alpha$ before amyloidosis prevents synaptic deficits in an Alzheimer's disease model," Neurobiology of Aging, vol. 47, pp. 41-49, 2016.

[68] C. Verbeeck, A. Carrano, P. Chakrabarty, J. L. Jankowsky, and P. Das, "Combination of A $\beta$ Suppression and Innate Immune Activation in the Brain Significantly Attenuates Amyloid Plaque Deposition," The American Journal of Pathology, vol. 187, no. 12, pp. 2886-2894, 2017.

[69] Y. Liu, W. Chen, Y. Lin, P. Lu, S. Hsieh, and I. H. Cheng, "Amelioration of amyloid- $\beta$-induced deficits by DcR3 in an Alzheimer's disease model," Molecular Neurodegeneration, vol. 12, no. 1, 2017.

[70] J. Yang, J. Kou, R. Lalonde, and K.-I. Fukuchi, "Intracranial IL-17A overexpression decreases cerebral amyloid angiopathy by upregulation of ABCA1 in an animal model of Alzheimer's disease," Brain, Behavior, and Immunity, vol. 65, pp. 262-273, 2017.

[71] I. Russo, L. Caracciolo, D. Tweedie et al., "Erratum: 3,6'Dithiothalidomide, a new TNF- $\alpha$ synthesis inhibitor, attenuates the effect of $\mathrm{A} \beta$ 1-42 intracerebroventricular injection on hippocampal neurogenesis and memory deficit (Journal of Neurochemistry (2012) 122 (1181-1192))," Journal of Neurochemistry, vol. 123, no. 4, p. 645, 2012.

[72] E. R. Detrait, B. Danis, Y. Lamberty, and P. Foerch, "Peripheral administration of an anti-TNF- $\alpha$ receptor fusion protein counteracts the amyloid induced elevation of hippocampal TNF- $\alpha$ levels and memory deficits in mice," Neurochemistry International, vol. 72, no. 1, pp. 10-13, 2014.

[73] D. Tweedie, R. A. Ferguson, K. Fishman et al., "Tumor necrosis factor- $\alpha$ synthesis inhibitor 3,6'-dithiothalidomide attenuates 
markers of inflammation, Alzheimer pathology and behavioral deficits in animal models of neuroinflammation and Alzheimer's disease," Journal of Neuroinflammation, vol. 9, 2012.

[74] J. T. Rogers, L. M. Leiter, J. McPhee et al., "Translation of the Alzheimer amyloid precursor protein mRNA is up- regulated by interleukin-1 through 5'-untranslated region sequences," The Journal of Biological Chemistry, vol. 274, no. 10, pp. 6421-6431, 1999.

[75] Y.-F. Liaoi, B.-J. Wang, H.-T. Cheng, L.-H. Kuo, and M. S. Wolfe, "Tumor necrosis factor- $\alpha$, interleukin- $1 \beta$, and interferon- $\gamma$ stimulate $\gamma$-secretase-mediated cleavage of amyloid precursor protein through a JNK-dependent MAPK pathway," The Journal of Biological Chemistry, vol. 279, no. 47, pp. 49523-49532, 2004.

[76] M. Yamamoto, T. Kiyota, M. Horiba et al., "Interferon- $\gamma$ and tumor necrosis factor- $\alpha$ regulate amyloid- $\beta$ plaque deposition and $\beta$-secretase expression in Swedish mutant APP transgenic mice," The American Journal of Pathology, vol. 170, no. 2, pp. 680-692, 2007.

[77] J. Hardy and D. J. Selkoe, "The amyloid hypothesis of Alzheimer's disease: progress and problems on the road to therapeutics," Science, vol. 297, no. 5580, pp. 353-356, 2002.

[78] D. Goldgaber, H. W. Harris, T. Hla et al., "Interleukin 1 regulates synthesis of amyloid $\beta$-protein precursor mRNA in human endothelial cells," Proceedings of the National Acadamy of Sciences of the United States of America, vol. 86, no. 19, pp. 7606-7610, 1989.

[79] B. E. Slack, L. K. Ma, and C. C. Seah, "Constitutive shedding of the amyloid precursor protein ectodomain is up-regulated by tumour necrosis factor- $\alpha$ converting enzyme," Biochemical Journal, vol. 357, no. 3, pp. 787-794, 2001.

[80] J. W. Lee, Y. K. Lee, D. Y. Yuk et al., "Neuro-inflammation induced by lipopolysaccharide causes cognitive impairment through enhancement of beta-amyloid generation," Journal of Neuroinflammation, vol. 5, article no. 37, 2008.

[81] P. He, Z. Zhong, K. Lindholm et al., "Deletion of tumor necrosis factor death receptor inhibits amyloid $\beta$ generation and prevents learning and memory deficits in Alzheimer's mice," The Journal of Cell Biology, vol. 178, no. 5, pp. 829-841, 2007.

[82] E. Paouri, O. Tzara, S. Zenelak, and S. Georgopoulos, "Genetic deletion of tumor necrosis factor- $\alpha$ attenuates amyloid- $\beta$ production and decreases amyloid plaque formation and glial response in the 5xfad model of Alzheimer's disease," Journal of Alzheimer's Disease, vol. 60, no. 1, pp. 165-181, 2017.

[83] J. D. Buxbaum, K.-N. Liu, Y. Luo et al., "Evidence that tumor necrosis factor $\alpha$ converting enzyme is involved in regulated $\alpha$ secretase cleavage of the Alzheimer amyloid protein precursor," The Journal of Biological Chemistry, vol. 273, no. 43, pp. 2776527767, 1998. 


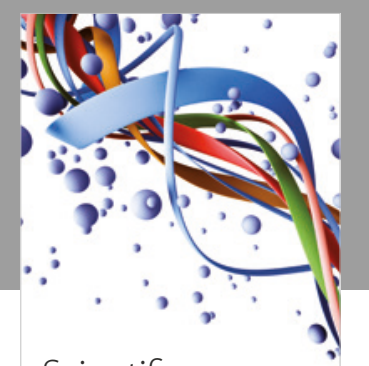

Scientifica
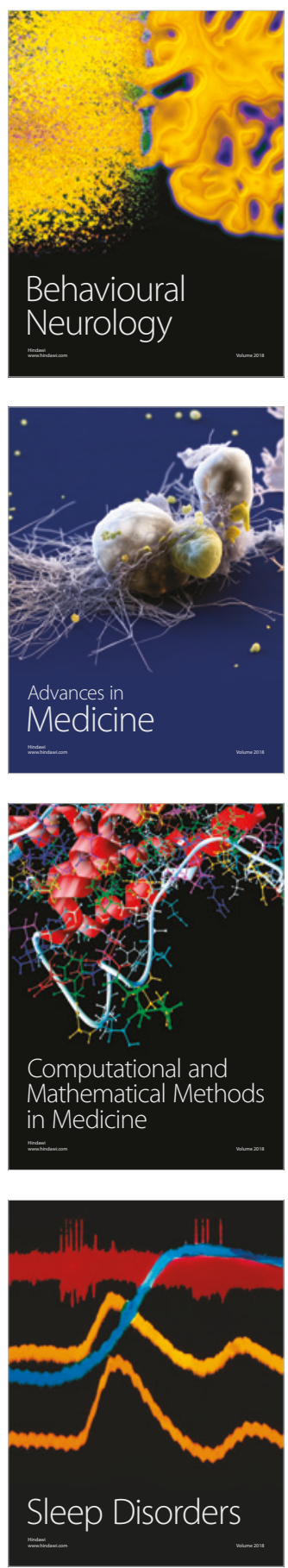

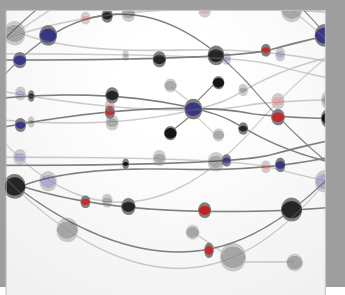

The Scientific World Journal

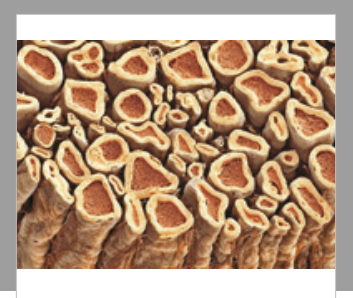

Case Reports in

Neurological Medicine

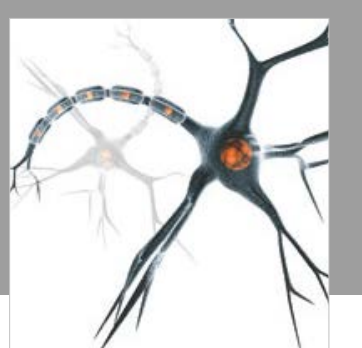

Neural Plasticity

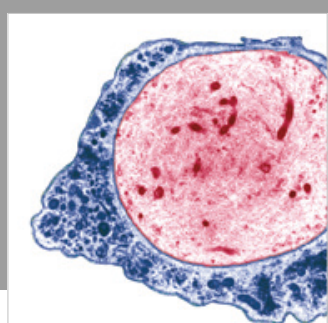

Multiple Sclerosis

International

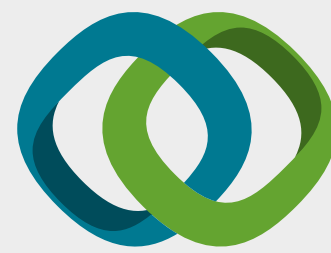

Hindawi

Submit your manuscripts at

www.hindawi.com
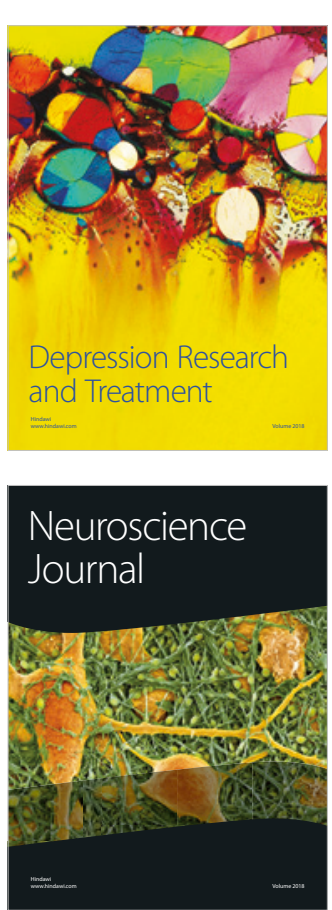

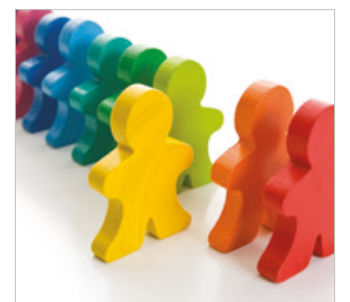

Autism

Research and Treatment
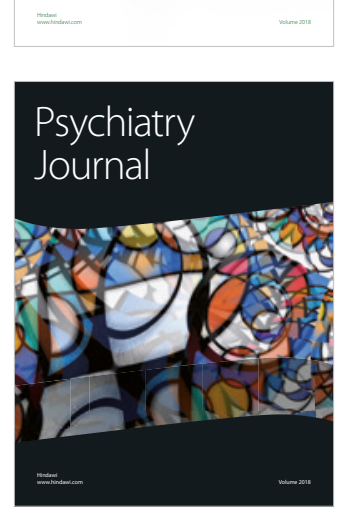
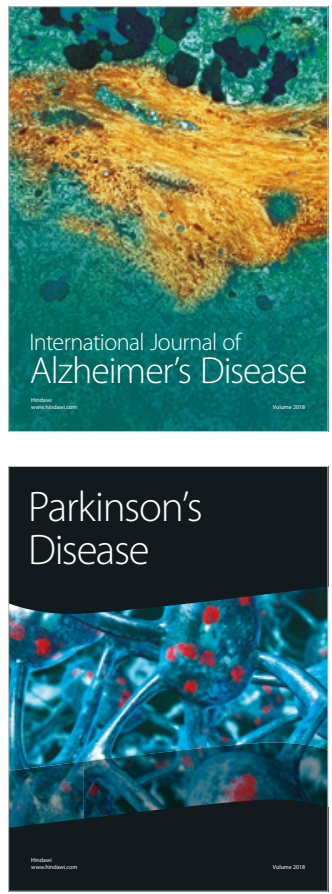
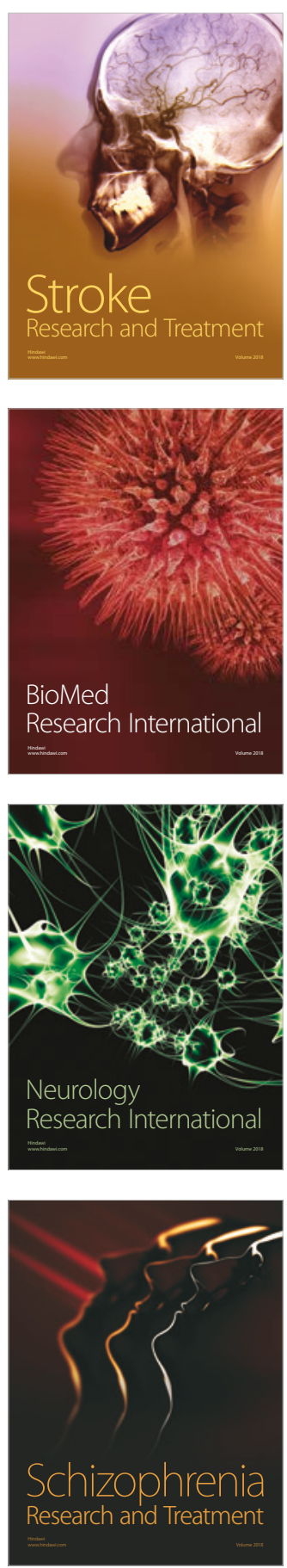